\title{
Percepção de amabilidade e hostilidade para com estrangeiros: um estudo qualitativo ${ }^{1}$
}

\author{
Perception of friendliness and hostility to foreigners: a qualitative study
}

\author{
Sonia Maria Guedes Gondim² \\ Elza Maria Techio ${ }^{3}$ \\ Daniela Cristina Ribeiro de Lima ${ }^{4}$ \\ lago Andrade Carias ${ }^{5}$ \\ Saulo Roger Moniz Pacheco Lima ${ }^{6}$ \\ Juliana Becker Souza7 \\ Ana Carolina Rocha Oliveira ${ }^{8}$ \\ Ludmila Magalhães da Silva ${ }^{9}$
}

\begin{abstract}
RESUMO: O estudo analisa a percepção dos imigrantes sobre a sua experiência no Brasil com base em 11 relatos, obtidos mediante apresentação de duas mesas redondas e entrevistas individuais durante um Seminário. Utilizou-se do procedimento de análise de conteúdo temática com o auxílio do software de análise qualitativa ATLAS.ti. As categorias temáticas de análise foram: emoções negativas e positivas de brasileiros para com imigrantes; manifestações comportamentais de amabilidade ou hostilidade para com o imigrante; experiências positivas ou negativas no Brasil. Os achados reúnem evidências da presença de emoções intergrupais positivas e comportamentos positivos, mas também de emoções e comportamentos negativos dos brasileiros para com os estrangeiros. Esta ambiguidade coloca em xeque a crença compartilhada de que o Brasil é um país hospitaleiro.
\end{abstract}

Palavras-chave: imigração; emoções intergrupais; preconceito; discriminação; experiências migratórias.

ABSTRACT: This study analyzing immigrants' perception on their experiences in Brazil based on 11 different reports, gathered from two round tables and the personal interviews obtained during a Seminar. A thematic analysis was used with the support of a software of qualitative data analysis ATLAS.ti. The thematic categories of analyses were the negative and positive Brazilian emotions towards immigrants; behavioral manifestations of friendliness and hostility, and negative and positive experiences in Brazil. The results show the presence of intergroup positive emotions and positive behaviors, but also Brazilian negative behaviors and emotions towards immigrants. This ambiguity call into question the shared belief about Brazil as a hospitable country.

Keywords: imigration; intergroup emotions; prejudice; discrimination; migration experiences.

\footnotetext{
1 Financiamento: CNPq

2 Professora do Instituto de Psicologia da Universidade Federal da Bahia - Salvador, BA, Brasil. E-mail: sggondim@gmail.com.

3 Professora do Instituto de Psicologia da Universidade Federal da Bahia - Salvador, BA, Brasil.

4 Voluntária do Grupo de Pesquisa Emoções e Afetos no Trabalho coordenado pela Professora Sonia Gondim na Universidade Federal da Bahia - Salvador, BA, Brasil.

${ }^{5}$ Graduando em Psicologia e Bolsista PIBIC/CNPq da Universidade Federal da Bahia - Salvador, BA, Brasil.

${ }^{6}$ Graduando em Psicologia e Bolsista PIBIC/ FAPESB da Universidade Federal da Bahia - Salvador, BA, Brasil.

${ }^{7}$ Graduanda em Psicologia e Bolsista PIBIC/CNPq da Universidade Federal da Bahia - Salvador, BA, Brasil.

${ }^{8}$ Graduanda em Psicologia e Bolsista PIBIC/ FAPESB da Universidade Federal da Bahia - Salvador, BA, Brasil.

${ }^{9}$ Graduanda em Psicologia e Bolsista PIBIC/ FAPESB da Universidade Federal da Bahia - Salvador, BA, Brasil.
} 


\section{Introdução}

O presente estudo teve o objetivo de analisar as percepções de imigrantes sobre a amabilidade e hostilidade de brasileiros. A migração está na base da constituição da sociedade brasileira. No processo de colonização e posteriormente durante o desenvolvimento da indústria nacional no final do século XIX e início do século XX, inúmeros estrangeiros migraram para o Brasil a trabalho (Foot \& Leonardi, 1982). Mais recentemente, observa-se um novo fluxo migratório no país (Brzozowski, 2012) decorrente de novas crises econômicas, políticas, religiosas e de catástrofes naturais.

A crise econômica mundial de 2008, somada ao desenvolvimento socioeconômico e ao reposicionamento geopolítico do Brasil, alteraram os processos migratórios (Cavalcanti, Oliveira \& Tonhati, 2014). Este cenário está passando por novas mudanças com a crescente crise econômica, social e política nacional dos últimos dois anos, não contempladas no escopo, no estudo que será descrito neste artigo, tendo em vista que os dados foram coletados no final de 2014, quando a crise ainda não era tão marcante.

Dados do censo demográfico brasileiro de 2010 apontavam aumento no número de imigrantes na última década e o retorno de brasileiros que estavam fora do país. O número de imigrantes passou de 143 mil pessoas entre 1995 e 2000 para 268 mil, entre 2005 e 2010 (IBGE, 2010). Informações do Comitê Nacional para os Refugiados (CONARE), vinculado ao Ministério da Justiça do Brasil (2015), indicam aumento no número de refugiados que procuram o Brasil. O Brasil acolheu, em 2014, 2.320 refugiados vindos em sua maioria da Síria e de Angola. O número é três vezes maior que o de 2013, e conforme dados sobre a concessão de autorizações para trabalhar fornecidos pela Coordenação Geral da Imigração do Ministério do Trabalho e Emprego (CGig/MTE), o somatório das autorizações permanentes e temporárias entre 2011 e 2013 foi de 200.450. Segundo dados da Relação Anual de Informações Sociais (RAIS/MTE), o número de estrangeiros com vínculo no mercado de trabalho formal no Brasil aumentou aproximadamente $51 \%$ no mesmo período. Dentre estes estrangeiros, destacam-se haitianos (814 em 2011, e 14.579 em 2013), portugueses (12.572), bolivianos (9.478), argentinos (9.089), paraguaios (8.550), e chilenos (8.500) (Cavalcanti et al., 2014).

Nesse cenário, Gondim et al. (2013), Souza (2013) e Menezes (2000) ressaltaram que os fluxos migratórios convertem-se em um problema de relevância para a ciência, pelas consequências psicossociais decorrentes das novas formas de relações entre os países, contribuindo para acirrar a concorrência no mercado de trabalho entre nativos e estrangeiros. Analisar as relações intergrupais entre brasileiros e imigrantes que buscam trabalho e melhores condições de vida no Brasil, pode vir a contribuir na compreensão das percepções de ameaça, no preconceito e na discriminação a que estão expostos os que ultrapassam suas fronteiras territoriais de origem.

\section{Emoções intergrupais}

A Teoria das Emoções Intergrupais oferece bases para compreender as relações entre os diferentes grupos sociais (Mackie, Smith \& Ray, 2008). A premissa é que ao ocorrer identificação dos indivíduos com o seu grupo de pertencimento, as características grupais tornam-se parte do self, adquirindo assim, significância socioemocional. Em sendo o grupo significativo, os objetos e eventos que fazem parte das particularidades do grupo são avaliados como relevantes e incorporados ao autoconceito (Smith, Seger \& Mackie, 2007). 
Emoções intergrupais podem influenciar nas condutas de aproximação ou afastamento a grupos sociais (Mackie, Devos, \& Smith, 2000; Mackie et al., 2008) e sugerem predizer a percepção de hostilidade de brasileiros para com estrangeiros (Gondim et al., 2013). Tais emoções também encontram-se relacionadas à manifestação de estereótipos e comportamentos de hostilidade (Cuddy \& Fiske, 2007), como as que ocorrem entre grupos historicamente rivais da Irlanda do Norte (católicos e protestantes) (Tam et al., 2007). O preconceito pode afastar os nativos dos imigrantes, ativando comportamentos discriminatórios, impulsionados pelo forte sentimento de repugnância (Hodson \& Costelo, 2007).

\section{Preconceito e discriminação}

O preconceito é definido como atitudes negativas direcionadas a uma pessoa que supostamente apresenta as mesmas características negativas atribuídas ao seu grupo social de pertencimento (Allport, 1954). Os preconceitos, na perspectiva de Lima (2013), são atitudes baseadas em julgamentos antecipados constituídos por componentes cognitivos (ex.: crenças, estereótipos), afetivos (ex.: antipatias, aversões) e volitivos (ex.: discriminação). Atualmente, a definição de preconceito associada às emoções negativas foi sendo substituída pela negação ou ausência de emoções positivas sentidas e expressas para com os membros dos exogrupos minoritários (Meertens \& Pettigrew, 1997). Os estereótipos são entendidos como crenças ou características socialmente compartilhadas atribuídas aos membros de determinado grupo social (Tajfel, 1982), e representam aspectos cognitivos do preconceito. Servem para justificar, racionalizar e legitimar as interações e sistemas sociais (Jost, Kivetz, Rubini, Guermandi, \& Mosso, 2005). Os estereótipos negativos, quando associados às emoções intergrupais negativas e à percepção de ameaça, fortalecem os processos discriminatórios (Cottrell \& Neuberg, 2005; Smith, 1993; Stephan et al., 2002).

A literatura aponta que as emoções intergrupais e a percepção de ameaça, principalmente em momentos de crise econômica, contribuem para a explicação da percepção de discriminação (Gondim et al., 2013; Pereira, Vala, \& Costa-Lopes, 2010). Outros estudos salientam a falta de amparo que imigrantes encontram no país de destino, tendo sua trajetória marcada por violações de direitos, semelhante à realidade encontrada no Brasil (Staffen \& Nistler, 2014). Os imigrantes também são comumente responsabilizados pelo aumento de índices de criminalidade nas cidades em que migram, mesmo quando não corroborado por dados oficiais (Tamer \& Pozzeti, 2013).

A origem étnica/nacionalidade, segundo Vilela (2011), tem impacto sobre a posição que o imigrante irá ocupar no mercado de trabalho no país para o qual migra. A origem étnica, quando associada a estereótipos negativos, parece interferir nas diferentes percepções dos nativos sobre os estrangeiros. A percepção de ameaça, principalmente em épocas de crise econômica, pode incitar comportamentos de hostilidade ou amabilidade para com os imigrantes. Uma das maneiras de se avaliar esses comportamentos é se aproximar dos contextos onde os imigrantes se sentem livres para expressar seus sentimentos sobre como são recebidos pelos brasileiros. Isto justifica o presente estudo qualitativo que teve como objeto de análise o 30 Seminário Vozes e Olhares Cruzados, promovido pela Missão Paz, entidade religiosa com sede em São Paulo e que se dedica à causa do imigrante há várias décadas. No referido seminário, os imigrantes foram convidados a relatar suas experiências durante o período de permanência no Brasil. 


\section{Missão Paz e a Casa do Migrante ${ }^{10}$}

A Missão Paz de São Paulo (MP) é uma instituição religiosa dirigida e mantida pelos Missionários Scalabrinianos e colaboradores, cujo objetivo é acolher, integrar e celebrar a vida dos imigrantes e refugiados. A Casa do Migrante, o Centro de Estudos Migratórios e o Centro Pastoral e de Mediação dos Migrantes compõem a estrutura da instituição.

Decorrente do sucateamento da estrutura do Estado de São Paulo e da antiga hospedaria do imigrante (transformada no museu da imigração e, posteriormente, no memorial do imigrante), a Casa do Migrante (CM) tornou-se um espaço apropriado para acolher o crescente fluxo de migrantes no estado a partir dos anos 1940. Os imigrantes podem se hospedar pelo período estimado de seis meses. Nos últimos anos, imigrantes de 72 nacionalidades estiveram na Casa, e entre Janeiro e Novembro de 2014 acolheu-se em torno de 11 mil pessoas, sendo a maioria composta por haitianos que entraram no Brasil atravessando o estado do Acre.

O Centro de Estudos Migratórios realiza pesquisas sobre migração e condições de vida dos migrantes, e divulga dados, relatos e experiências dos imigrantes ou pessoas envolvidas no processo de integração e mediação de mão de obra. Desde 1988 publica a revista TRAVESSIAS -, e também realiza assessoramento e acompanhamento jurídico, social, cultural e religioso.

No final dos anos 1970, migrantes latino-americanos começaram a frequentar a Casa, que passou a atuar como espaço de acolhimento. Em 1998, iniciou-se um período de transição com a vinda de imigrantes com maior qualificação profissional (cursos técnicos e universitários, capacitação e especialização técnica).

Embora o Centro de Pastoral já existisse há 20 anos, a partir de 2012 ele foi ampliado e passou a incluir ações de Mediação dos Migrantes, realizando atendimento e orientação jurídica na tramitação e regularização de documentação junto aos órgãos competentes. Promove também apoio sociocultural, além de facilitar a inserção no mercado de trabalho. Para melhor aproveitamento dos recursos materiais e de pessoal, o Centro Pastoral e de Mediação é organizado em eixos temáticos. Estes eixos comtemplam ações voltadas para educação, saúde, comunidade, família e trabalho. No que tange ao eixo trabalho, uma equipe técnica presta apoio jurídico e documental aos imigrantes. A referida equipe inclui assistentes sociais, advogados, psicólogos e voluntários, que fazem a mediação, facilitando contatos interpessoais e institucionais (escolas, creches, polícia federal, consulado, rede de saúde, etc.).

O eixo trabalho atua em duas direções. Uma voltada para o imigrante que procura trabalho, ao contrário da segunda que está dirigida ao empregador. Ambos recebem orientações sobre a legislação trabalhista brasileira. Até 30 de outubro de 2014, o eixo trabalho havia inserido no mercado de trabalho, aproximadamente, 2.344 imigrantes, com casos de insucesso menor que $2,5 \%$.

Uma das atividades da Missão Paz é dar voz aos imigrantes. Para isso, foi criado o Seminário Vozes e Olhares Cruzados que está na terceira edição. São convidados imigrantes que passaram pela Casa do Migrante (CM) e se encontram inseridos no mercado de

\footnotetext{
${ }^{10}$ As informações sobre a Missão Paz foram obtidas a partir da entrevista com um ex-diretor da revista TRAVESSIA e colaborador da missão Paz e dos relatos do Padre Paolo Parise e da assistente social da Missão durante as mesas do Seminário.
} 
trabalho, os quais relatam suas experiências afetivas com brasileiros no processo de adaptação no país.

\section{Método}

Pela informalidade das manifestações neste tipo de evento, considerou-se pertinente usar este espaço para a realização de um estudo qualitativo com foco no acontecimento (Pires, 2008), em que se poderia ter acesso à percepção da amabilidade e hostilidade de brasileiros para com estrangeiros que migram para trabalhar no Brasil.

\section{O seminário}

O Seminário Vozes e Olhares Cruzados, uma iniciativa do diretor do Centro de Estudos Migratórios, realiza-se anualmente com diferentes temáticas, sendo considerado um espaço em que o migrante pode "manifestar o seu protagonismo, visto a dificuldade que é expressar-se quando ainda em dependência dos atendimentos da Casa e do Centro Pastoral de Mediação do Migrante".

A terceira edição do seminário, ocorrida em 07 de Novembro de 2014 e transmitida ao vivo via web rádio, teve como tema "Trabalho: entre sonho e realidade", dando visibilidade ao trabalho de mediação da Missão Paz na inserção do imigrante no mercado de trabalho. 0 seminário foi composto por três apresentações culturais, duas mesas redondas, momentos de debates com a plateia, roda de conversação com os participantes do seminário (estudantes, professores, pesquisadores, comunidades, etc.) e os imigrantes presentes, além do lançamento da 74ㅇe edição da Revista Travessias, intitulada "Imigração Paraguaia em São Paulo".

Durante as duas mesas redondas e o debate com a plateia houve a participação de imigrantes de diversas nacionalidades e de dois empresários brasileiros. Os imigrantes descreveram suas experiências e vivências relativas à inserção no mercado de trabalho, destacando dificuldades enfrentadas para obter a documentação, tipo de vínculo empregatício, e relações interpessoais com os brasileiros. Os empresários, por sua vez, relataram brevemente suas experiências ao contratarem imigrantes. As mesas duraram em média uma hora, com dez minutos aproximadamente para cada participante, seguido de debate.

\section{Participantes}

A principal fonte de coleta de dados foram os relatos dos imigrantes nas mesas redondas do evento. Para complementação dos dados, tendo em vista terem sido breves os relatos de imigrantes e empresários nessas mesas redondas, foram entrevistados três imigrantes - um haitiano, um congolês e um tongalês - e o ex-diretor da Revista Travessias. A entrevista com o ex-diretor da Revista contribuiu para contextualizar institucionalmente a Missão Paz. O reduzido número de entrevistas decorreu das dificuldades de acesso a esses imigrantes, muitos com receio de expor em detalhes sua experiência a desconhecidos.

As mesas foram compostas por imigrantes de origens diversas (Haiti, Congo, Tonga, Guiné-Bissau, Nigéria, Peru, Bolívia, Costa do Marfim), o Padre Paolo Parise, um dos 
responsáveis pela gestão da Missão Paz e organizador do seminário, a assistente social da instituição, e dois empresários brasileiros, um do ramo alimentício e outro de logística. Ambos haviam contratado imigrantes haitianos por mediação da Missão Paz. Não tivemos contato adicional com os dois empresários para além de sua breve participação na mesa redonda. Em sendo assim, a tabela 1 apresenta somente as características descritivas dos imigrantes participantes das mesas redondas e dos três entrevistados (P1, P2, e P3). As células não preenchidas na tabela 1 se devem à ausência de dados, tendo em vista que no breve relato feito na mesa redonda o imigrante não fez menção a isto.

Tabela 1 - Caracterização dos imigrantes participantes

\begin{tabular}{|c|c|c|c|c|c|c|c|c|c|c|c|}
\hline Participante & Origem & Idade & Sexo & $\begin{array}{l}\text { Com } \\
\text { quem } \\
\text { migrou }\end{array}$ & $\begin{array}{l}\text { Motivo da } \\
\text { Migração }\end{array}$ & $\begin{array}{c}\text { Pretensão } \\
\text { de volta } \\
\text { ao país }\end{array}$ & $\begin{array}{l}\text { Por onde } \\
\text { entrou } \\
\text { no } \\
\text { Brasil? }\end{array}$ & $\begin{array}{c}\text { Tempo } \\
\text { no } \\
\text { Brasil }\end{array}$ & $\begin{array}{l}\text { Tipo de } \\
\text { Trabalho }\end{array}$ & $\begin{array}{c}\text { Tempo } \\
\text { de } \\
\text { Trabalho }\end{array}$ & $\begin{array}{c}\text { Observações e } \\
\text { Comentários } \\
\text { Adicionais }\end{array}$ \\
\hline 1 & Congo & 26 & $M$ & Irmão & $\begin{array}{l}\text { Instabilidade } \\
\text { política no } \\
\text { país de } \\
\text { origem }\end{array}$ & Sim & $\begin{array}{l}\text { Porto de } \\
\text { Santos }\end{array}$ & $\begin{array}{c}6 \\
\text { meses }\end{array}$ & Cozinheiro & 4 meses & $\begin{array}{c}\text { Pretende } \\
\text { retornar ao } \\
\text { seu país assim } \\
\text { que a situação } \\
\text { política se } \\
\text { normalize. } \\
\text { Retornará ao } \\
\text { Haiti porque }\end{array}$ \\
\hline 2 & Haiti & 29 & $M$ & Sozinho & $\begin{array}{c}\text { Dificuldade } \\
\text { de trabalho } \\
\text { no Haiti }\end{array}$ & Sim & Acre & 3 anos & $\begin{array}{c}\text { Garçom e em } \\
\text { outras } \\
\text { funções }\end{array}$ & - & $\begin{array}{c}\text { não vive em } \\
\text { boas } \\
\text { condições no } \\
\text { Brasil, ganha } \\
\text { pouco. }\end{array}$ \\
\hline 4 & Bolívia & 38 & $M$ & Sozinho & $\begin{array}{l}\text { Política do } \\
\text { país de } \\
\text { origem } \\
\\
\text { Melhor } \\
\text { condição de } \\
\text { vida }\end{array}$ & Sim & $\begin{array}{l}\text { Minas } \\
\text { Gerais }\end{array}$ & $\begin{array}{c}3 \\
\text { meses }\end{array}$ & Pedreiro & $\begin{array}{l}1 \text { mês e } \\
\text { meio }\end{array}$ & $\begin{array}{c}\text { Segunda } \\
\text { experiência } \\
\text { de migração. } \\
\text { Migrou na } \\
\text { primeira vez } \\
\text { para a Guiné. } \\
\text { Primeiro } \\
\text { emprego foi } \\
\text { numa } \\
\text { confecção em } \\
\text { Minas Gerais. }\end{array}$ \\
\hline 5 & Haiti & & $M$ & - & $\begin{array}{c}\text { Melhor } \\
\text { condição de } \\
\text { vida }\end{array}$ & - & Acre & - & $\begin{array}{c}\text { Indústria } \\
\text { Farmacêutica }\end{array}$ & 3 meses & 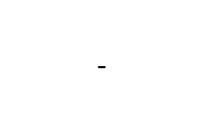 \\
\hline 6 & Peru & & $\mathrm{F}$ & Sozinha & - & Não & $\begin{array}{l}\text { Minas } \\
\text { Gerais }\end{array}$ & 5 anos & $\begin{array}{l}\text { Líder - } \\
\text { restaurante } \\
\text { japonês }\end{array}$ & - & $\begin{array}{c}\text { Foi } \\
\text { aconselhada a } \\
\text { renunciar a } \\
\text { nacionalidade, } \\
\text { ficou apátrida } \\
\text { até conhecer } \\
\text { a CM. }\end{array}$ \\
\hline 7 & Haiti & & $\mathrm{F}$ & - & $\begin{array}{c}\text { Melhor } \\
\text { condição de } \\
\text { vida }\end{array}$ & Não & - & 3 anos & Babá & $\begin{array}{l}1 \text { ano e } \\
9 \text { meses }\end{array}$ & $\begin{array}{c}\text { Ela está em } \\
\text { seu quarto } \\
\text { trabalho no } \\
\text { Brasil. } \\
\text { Pretende } \\
\text { trazer o filho e } \\
\text { o tio. }\end{array}$ \\
\hline 8 & $\begin{array}{c}\text { Costa } \\
\text { do } \\
\text { Marfim }\end{array}$ & 20 & $M$ & Sozinho & Estudos & Sim & Paraíba & 1 ano & $\begin{array}{l}\text { Trabalhos } \\
\text { informais }\end{array}$ & - & $\begin{array}{l}\text { Pretende } \\
\text { retornar ao } \\
\text { seu país assim } \\
\text { que concluir } \\
\text { os estudos. }\end{array}$ \\
\hline 9 & $\begin{array}{l}\text { Guine } \\
\text { Bissau }\end{array}$ & 27 & $M$ & Sozinho & - & - & Fortaleza & 2 anos & - & - & - \\
\hline
\end{tabular}




\section{Instrumentos e procedimentos de coleta}

A coleta de dados ocorreu entre os dias 6 e 8 de Novembro de 2014 em São Paulo, durante a realização do evento. Nessas datas, as coordenadoras da pesquisa com o auxílio de dois bolsistas de iniciação científica, conheceram as atividades da Missão Paz mediante o contato com o Padre Paolo Parise e entrevista com o ex-diretor da Revista Travessias. A equipe também filmou o " 3 ㅇ Seminário Vozes e Olhares Cruzados" para fins de registro dos relatos dos imigrantes e dos dois empresários brasileiros.

Além disso, foram realizadas entrevistas nas dependências da Casa do Migrante com três imigrantes residentes. As entrevistas foram realizadas com base em um roteiro semiestruturado que incluía dados sociodemográficos para a caracterização dos participantes. Para as entrevistas com os imigrantes na Casa do Migrante e o ex-diretor da Revista Travessias, foram utilizados aparelhos de gravação de áudio. A entrevista com o ex-diretor durou cerca de 30 minutos; as entrevistas individuais com imigrantes residentes na Casa do Migrante duraram entre 15 a 20 minutos (tempo menor talvez devido ao receio dos imigrantes de conversar com estranhos sobre sua situação no Brasil, além das dificuldades com o idioma português). 0 depoimento dos imigrantes nas mesas redondas durou entre 5 a 7 minutos.

\section{Roteiro de entrevista}

O roteiro semi-estruturado da entrevista com os imigrantes abordou os seguintes tópicos: i) história de vida (motivo da vinda, por que escolheram o Brasil); ii) experiência no Brasil (dificuldades e facilidades em sua chegada, regularização de sua situação no Brasil, de que forma encontrou o atual trabalho); iii) percepções das relações de trabalho com os brasileiros (as emoções ou sentimentos dos brasileiros para com imigrantes) e iv) contexto de trabalho (como se dá a relação com o chefe e os colegas de trabalho). A entrevista com o ex-diretor da Revista Travessias e membro atuante da Missão Paz teve como principal objetivo obter informações sobre a trajetória da entidade e sua atuação junto à comunidade de imigrantes ao longo de sua existência.

\section{Procedimentos de análise}

Os relatos foram gravados e transcritos segundo as orientações de Hammersley (2010) para procedimentos de análise categorial temática de conteúdo (Bardin, 1977; Bauer, 2002; Gondim \& Bendassolli, 2014) com o auxílio do software de análise qualitativa ATLAS.ti versão 7 (Friese, 2012). As transcrições das entrevistas e das gravações das mesas redondas foram codificadas e categorizadas no ATLAS.ti levando em conta os conceitos centrais do estudo: emoções intergrupais negativas e positivas de brasileiros para com imigrantes; manifestações comportamentais positivas e negativas para com o imigrante; e experiência positiva ou negativa no Brasil.

A opção por um sistema de categorização prévia decorreu principalmente das limitações impostas pela natureza do estudo: a de acompanhar a realização de um evento. A análise aprofundada de cada caso dificilmente poderia ser feita nestas circunstâncias. Cada participante tinha um tempo limitado ( 5 minutos) para expor sua história na mesa redonda e não se teve acesso a eles para fins de entrevista individual. As poucas tentativas feitas pela equipe não foram bem-sucedidas. Eles tinham receio de detalhar sua história a 
desconhecidos, o que é compreensível. Enfim, o caminho adotado para a análise interpretativa dos relatos nas mesas redondas e das entrevistas foi apoiar-se em um sistema categorial prévio para codificar os relatos de cada imigrante. Dois juízes independentes codificaram os relatos no ATLAS ti, tendo havido grande concordância entre eles. Em alguns poucos casos de discordância, o procedimento foi retomar o material transcrito para avaliar a pertinência da codificação e ou da categorização. A tabela 2 apresenta as categorias de análise, como exemplos do material codificado.

Tabela 2 - Categorias de Análise

\begin{tabular}{|c|c|c|c|}
\hline \multicolumn{2}{|l|}{ Categorias } & 0 que é? & Exemplos \\
\hline \multirow[b]{2}{*}{ Emoções Intergrupais } & Positivas & $\begin{array}{c}\text { São manifestações afetivas positivas } \\
\text { de brasileiros relatadas pelos } \\
\text { imigrantes. }\end{array}$ & $\begin{array}{l}\text { Amizade, tolerância, compreensão, boa } \\
\text { vontade, companheirismo, etc. }\end{array}$ \\
\hline & Negativas & $\begin{array}{c}\text { São manifestações afetivas negativas } \\
\text { de brasileiros relatadas pelos } \\
\text { imigrantes. }\end{array}$ & $\begin{array}{l}\text { Arrogância, repulsa, superioridade, } \\
\text { hostilidade, falsidade, etc. }\end{array}$ \\
\hline \multirow{2}{*}{$\begin{array}{l}\text { Manifestações } \\
\text { Comportamentais }\end{array}$} & Positivas & $\begin{array}{l}\text { São manifestações comportamentais } \\
\text { positivas (ou de amabilidade) } \\
\text { relatadas pelos imigrantes. }\end{array}$ & $\begin{array}{l}\text { Fazer amizade, ensinar as tarefas, } \\
\text { concordar com as ideias, elogiar, } \\
\text { valorizar a cultura do imigrante, etc. }\end{array}$ \\
\hline & Negativas & $\begin{array}{c}\text { São manifestações comportamentais } \\
\text { negativas (ou de hostilidade) relatadas } \\
\text { pelos imigrantes. }\end{array}$ & $\begin{array}{l}\text { Isolar, imitar sotaque, fingir que não } \\
\text { existem, criticar o trabalho, debochar ou } \\
\text { fazer piadas, etc. }\end{array}$ \\
\hline \multirow{2}{*}{ Experiências } & Positivas & $\begin{array}{c}\text { São as experiências positivas } \\
\text { vivenciadas pelos os imigrantes } \\
\text { durante sua permanência no Brasil. }\end{array}$ & \\
\hline & Negativas & $\begin{array}{c}\text { São as experiências negativas } \\
\text { vivenciadas pelos os imigrantes } \\
\text { durante sua permanência no Brasil. }\end{array}$ & \\
\hline
\end{tabular}

Embora um dos critérios de construção de categorias segundo Bardin (1977) seja o de exclusão, as categorias definidas para este estudo têm um caráter de complementaridade. 0 esforço de organização de categorias foi no sentido de tentar encontrar aspectos marcantes das relações intergrupais, em destaque a percepção de hostilidade e amabilidade de brasileiros para com imigrantes.

\section{Resultados}

Tendo em vista a importância de se colocar em destaque as percepções e sentimentos vividos por imigrantes na sua relação com brasileiros, optou-se por apresentar os resultados a partir da história de cada caso, com destaque para as experiências positivas/negativas, as evidências de emoções intergrupais positivas/negativas e as manifestações comportamentais positivas/negativas dos brasileiros para com os imigrantes no contexto de trabalho. Em outras palavras, procurou-se privilegiar na descrição dos resultados a história de cada imigrante, permitindo ao leitor visualizar nesta breve história as categorias teóricas analisadas. 


\section{Participante 1 (entrevista individual)}

P1 é do sexo masculino, tem 26 anos, e veio do Congo acompanhado pelo irmão, deixando a esposa e a filha. Chegou pelo Porto de Santos e estava no Brasil há seis meses. Sua saída do Congo foi motivada pela instabilidade política do país. O Brasil foi seu primeiro destino no exterior. Após quatro meses residindo na CM (Casa do Migrante), estava se estabelecendo em outro lugar.

Há quatro meses estava trabalhando como ajudante de cozinha. Conseguiu o emprego por indicação de um amigo da CM. Relata que trabalha com brasileiros e outros congoleses. Diz que sua relação com os brasileiros é boa (manifestação comportamental positiva), mas não dá exemplos dessa relação. Afirma que foi o seu chefe e seus colegas de trabalho brasileiros que o ensinaram a executar suas tarefas no restaurante (manifestação comportamental positiva). O entrevistado manifestava o seu contentamento com o trabalho "o mais importante é o trabalho" (experiência positiva).

Sobre suas expectativas ao chegar ao Brasil, assinalou que foi muito diferente do que vivenciou nos últimos meses. Descreve que no Congo ganhava muito mais com o seu trabalho do que aqui no Brasil (experiência negativa). Também enfatizou as diferenças culturais entre o Congo e o Brasil, exemplificando que no Congo não existiam problemas como o racismo (emoção intergrupal negativa). Relata que se sentia discriminado por comportamentos de alguns brasileiros no metrô e nos ônibus de São Paulo: "Ele não vai querer sentar porque você já está sentado" (manifestação comportamental negativa). A respeito da possibilidade de que tal comportamento discriminatório acontecesse no seu trabalho, o participante fica em silêncio. Manifesta o desejo de retornar ao seu país caso haja mudanças na situação política do Congo: "Eu vou voltar para o meu país (...) se no meu país mudar a política".

\section{Participante 2 (entrevista individual)}

P2 é do sexo masculino, tem 29 anos e veio do Haiti. Estava com dificuldades de encontrar emprego em seu país depois do terremoto. Veio ao Brasil por sugestão do chefe do Exército Brasileiro que participava da missão de reconstrução do país. Relata que esse militar afirmava que no Brasil teria a oportunidade de mudar de vida (manifestação comportamental positiva). Veio ao Brasil não apenas para trabalhar, mas porque imaginou que teria mais oportunidade para aprender. Havia terminado o ensino médio e decidiu trabalhar para pagar seus estudos. Chegou ao Brasil com 27 anos em 2012, conseguiu a documentação após permanecer seis meses no Acre, em seguida foi para São Paulo estabelecendo-se na $\mathrm{CM}$ por quatro meses, enquanto aprendia o português. Sobre o processo de chegada ao Brasil, lembra que é uma situação complicada e muito triste, em que muitos choram por não terem onde dormir e o que comer (experiência negativa), mas considera que foi uma experiência muito boa, por ter aprendido um pouco sobre a vida.

Mencionou que no Brasil há poucas opções de trabalho, pois oferecem a eles [imigrantes] apenas trabalho na construção civil, o que parece ser avaliado como de menor status profissional, e diz: "aí chega lá não tem, construção civil [...] só escravo" (experiência negativa). Trabalhou em diversos empregos, formais e informais, porém, relatou dificuldade em permanecer nos empregos devido às condições financeiras e de moradia (experiência negativa). Afirma que com o dinheiro recebido não era possível fazer compras e insuficiente 
para fazer todas as refeições do dia (experiência negativa). Sobre as condições de moradia, mencionou que o aluguel em São Paulo é caro e por isso divide um quarto pequeno com aproximadamente quatro pessoas (experiência negativa).

Relata ter sofrido preconceito no trabalho e o quanto o fazia passar mal, ao ponto de já ter sido hospitalizado por isso (experiência negativa). Uma vez um colega de trabalho contou para ele que a gerente havia dito que ele não tomava banho e estava fedendo. Outra vez, um chefe disse a ele: "ah, você não é daqui, você é pobre, você tá [...] escravo" (manifestação comportamental negativa). Porém, também ressalta que há exceções, a exemplo desse colega que o avisou sobre o comportamento da gerente e que ele o descreveu como amigo (manifestação comportamental positiva). Afirma que há pessoas de coração bom, geralmente os colegas nordestinos (emoção intergrupal positiva).

Menciona que esta é mesma situação enfrentada por outros imigrantes haitianos, e por isso optou por retornar ao Haiti. Embora não tenha dinheiro para pagar a passagem de volta, por ser muito cara, seus familiares haitianos enviaram dinheiro para ajudá-lo. Relata que seus familiares acompanham o que acontece com ele e pensam que não há futuro para ele no Brasil. A impressão que o haitiano tem é que ele se encontra do mesmo jeito de quando chegou, porque "não é trabalhar como meio para chegar em algum lugar, é trabalhar por trabalhar". Descreve ter imaginado que a imigração seria diferente, tinha boas expectativas e vivenciou muitas dificuldades (experiência marcante negativa). Embora queira muito ir embora, afirma que fica triste por deixar as amizades que fez durante sua estadia no Brasil (emoção intergrupal positiva).

\section{Participante 3 (entrevista individual)}

P3 é do sexo masculino, tem 38 anos e é do Reino de Tonga (Polinésia, Oceania). Migrou para o Brasil vindo da Guiné Equatorial, para onde já havia migrado à procura de trabalho. Por problemas políticos e complicações para trabalhar na Guiné, resolveu vir ao Brasil, deixando dois filhos pequenos (de 3 e 5 anos). Está há três meses no país e conseguiu trabalho na construção civil, como pedreiro, depois de um mês e meio (experiência marcante positiva). Conheceu um empreiteiro brasileiro que o ajudou a conseguir sua carteira de trabalho para assiná-la (o que ainda não aconteceu) e o tem auxiliado na busca de novas alternativas de serviço com melhor remuneração (manifestação comportamental positiva). Relatou ainda que sabe da discriminação que os negros sofrem no mundo todo (experiência negativa), mas que não sente isso diretamente e de forma explicita. Disse que tem uma boa relação com seus colegas de trabalho (onde, por sinal, é o único negro), afirmando que todos o ajudam e dialogam (manifestação comportamental positiva e experiência positiva). Revelou que pretende trazer os filhos para o Brasil assim que se estabilizar financeiramente.

\section{Participante 4 (mesa redonda)}

P4 é do sexo feminino, oriunda da Bolívia e tem dois filhos. Migrou para o Brasil à procura de trabalho e melhores condições de vida. Para entrar no país foi ao Paraguai e de lá viajou para Minas Gerais, onde permaneceu por cinco meses trabalhando numa confecção das sete da manhã às dez da noite, de segunda a sábado. Nesse trabalho, sua remuneração era inferior àquela que recebia na Bolívia (experiência negativa). Sentia-se frustrada por isso, 
mas permaneceu no trabalho, porque tinha que pagar a dívida da viagem para o Brasil. Além disso, outras despesas como alimentação e moradia eram descontadas do seu salário e nos fins de semana só alimentava-se uma vez ao dia (experiência negativa). Assim que quitou as dívidas, mudou-se para São Paulo em busca de melhores oportunidades. Em São Paulo, procurou o consulado da Bolívia, mas "não fui bem tratada", recusaram-se a lhe ajudar (manifestação comportamental negativa). Por fim, encontrou o acolhimento na CM (manifestação comportamental positiva), "onde pôde morar e... com segurança e com confiança... pôde buscar essa oportunidade que tanto queria encontrar".

\section{Participante 5 (mesa redonda)}

P5 é do sexo masculino, veio do Haiti e entrou no Brasil cruzando a fronteira com a Bolívia, no Acre. Relata a sua desilusão para com as expectativas de uma vida melhor no Brasil: "Quando eu cheguei aqui no Brasil, uma pessoa fala 'ah, vou chegar lá, aqui no Brasil, trabalhar, criar minha vida, ganhar muito', todo haitiano pensa isso, pensa que vai chegar aqui trabalhar com muito, muito, muito dinheiro e manter a sua família, manter ele, mas não é a realidade".

Descreve que o seu primeiro trabalho foi no Acre na empresa $X$ carregando $e$ descarregando caminhão. Relata que os colegas e a empresa o tratavam muito bem (manifestação comportamental positiva/experiência positiva). No entanto, não pôde ficar muito tempo devido a um problema na coluna vertebral provocado pelo terremoto no Haiti em 2010.

Depois do Acre, foi para Bahia trabalhar como intérprete em um hotel. Na Bahia também fazia "bicos" como jardineiro, cozinheiro, etc. Resolveu ir para São Paulo devido à precária cobertura de celular na localidade em que estava estabelecido o que dificultava a comunicação com a família no Haiti.

Em São Paulo, foi à CM permanecendo por um mês quando conseguiu emprego em uma empresa farmacêutica, onde trabalha há três meses. Relata que a experiência nesse serviço está sendo boa (experiência positiva). Sobre o Brasil, descreve que apesar dos inconvenientes que vêm passando desde sua chegada, a sua experiência está sendo positiva (experiência positiva).

\section{Participante 6 (mesa redonda)}

P6 é do sexo feminino, licenciada em educação no Peru e já está há 5 anos no Brasil. Chegou ao Brasil primeiramente na cidade de Curvelo - MG e, por ser licenciada conseguiu trabalho como professora de espanhol em duas escolas privadas. Porém, recebia menos que os demais professores. Relata que em determinada ocasião os outros professores receberam aumento de salário, enquanto o dela diminuiu (manifestação comportamental negativa). Por esse motivo, pediu demissão e foi trabalhar em um restaurante como garçonete. Começou ganhando bem e recebia semanalmente; depois passou a receber quinzenalmente e chegou a não receber, mesmo tendo trabalhado (experiência negativa). Disse: "É muito triste porque quando um estrangeiro sai do seu país, a gente não só traz roupa, a gente traz sonhos, a gente traz metas, a gente sonha com o futuro que dar a família [...] há pessoas que te veem nessa fraqueza, 'não tem documentação, não tem carteira, então vamos lá, né, é boa funcionária, vamos aproveitar'. Aí as empresas vão, os patrões vão crescendo e vão se 
aproveitando da pessoa e a pessoa aí passando fome, sem sonhos, sem dignidade, sem roupa" (manifestação comportamental negativa).

Quando chegou a CM não conhecia São Paulo, recebeu abrigo e a ajuda jurídica para conseguir a identidade e a carteira de trabalho (manifestação comportamental positiva e experiência positiva). A entrevistada passou por situação bastante difícil em relação à documentação, sendo instruída por um advogado em Minas Gerais a renunciar à sua nacionalidade (manifestação comportamental negativa), ficando apátrida. Tal recomendação a deixou em situação crítica, principalmente para conseguir emprego e novos documentos (experiência negativa). Relata que na ocasião se encontrava desamparada, em situação de desespero, chegou inclusive a dormir na rua (experiência negativa).

Relata que sofreu muito até conseguir conquistar a vida que tem hoje, a documentação e um emprego no qual acabou de ser promovida (experiência positiva). Atualmente, recebe o pagamento com direito às horas-extras, mobilidade e hora de almoço (experiência positiva), o que para ela era uma novidade e motivo de alegria, "porque nos outros restaurantes a gente tinha que comer rápido para você voltar a trabalhar, quase engolindo a comida" (experiência negativa).

\section{Participante 7 (mesa redonda)}

P7 é do sexo feminino, veio do Haiti e está há três anos no Brasil. Deixou o filho, os irmãos e o tio na República Dominicana. Relata que ao chegar a São Paulo ficou em um hotel por três dias. Em meio às suas preocupações com a estadia no hotel, encontrou uma pessoa que a indicou à $\mathrm{CM}$, onde permaneceu por vinte e dois dias até que, pela mediação do eixo trabalho, encontrou emprego em um frigorífico em outro Estado. Nesse trabalho se manteve por um mês. Alega que "lá o lugar onde eles coloca nós, só nós pretos, eles coloca. Os brasileiros eles coloca em outro lugar" (manifestação comportamental negativa).

Devido às péssimas condições de trabalho, abandona o emprego e volta a São Paulo. Por intermédio da Missão Paz consegue outro emprego, desta vez como atendente em um restaurante. Permaneceu nesse emprego por seis meses, porque não estava ganhando o esperado para manter-se no Brasil e ajudar a sua família no exterior (experiência negativa).

Em sua terceira experiência de trabalho no Brasil, teve a promessa de que iria trabalhar como babá, para cuidar de uma criança de quatro anos. No entanto, a empregadora assinou sua carteira de trabalho como doméstica (manifestação comportamental negativa), alegando não ter condições de pagá-la como babá. Ao comunicar a sua insatisfação, a empregadora decidiu indicá-la a outra pessoa (manifestação comportamental positiva), lugar onde se encontra há um ano e nove meses. A sua carteira de trabalho foi assinada e os seus patrões a "tratam bem" (experiência positiva). Relata que não aspira retornar ao seu país, pois seu objetivo é continuar no Brasil até que "encontre uma vida melhor". A sua vontade é trazer o seu tio e o seu filho que estão na República Dominicana.

\section{Participante 8 (mesa redonda)}

P8, do sexo masculino, tem 20 anos e veio da Costa do Marfim para o Brasil em 2013 por meio de um programa de intercâmbio universitário em um Estado do nordeste. Não 
atingiu a nota mínima no exame de língua portuguesa para ingressar numa universidade brasileira, porém decidiu tentar outra vez no ano seguinte. Como possuía visto de estudante, não lhe era permitido exercer atividade remunerada no país. Tal impedimento causou grande dificuldade, uma vez que sua mãe não poderia lhe sustentar enquanto estivesse aqui. Quando informado pela polícia federal que não poderia permanecer no país porque não havia conseguido iniciar os estudos na universidade, vende o computador e compra uma passagem para São Paulo, onde esperava encontrar melhores oportunidades de trabalho e iniciar os estudos. Em São Paulo, teve contato com uma ONG que the auxiliou, principalmente, para conseguir iniciar os estudos. Para se sustentar, começou a fazer pequenos trabalhos informais, como limpar casas, lavar carros, dar banho em cachorros, apesar de em seu país de origem já ter concluído a graduação (experiência negativa).

\section{Participante 9 (mesa redonda)}

P9, do sexo masculino, tem 27 anos, originário da Guiné-Bissau. Chegou a Fortaleza em 2012. Depois, viajou para São Paulo, onde não conhecia ninguém e dormiu na rua. Foi encontrado pela polícia na Praça da Sé que o encaminhou para a CM, permanecendo por dois meses enquanto aguardava a documentação. Depois de regularizar sua situação, foi trabalhar em outro estado, por oito meses. Porém relata que essa empresa não pagava o salário nem queria assinar sua carteira de trabalho (manifestação comportamental negativa). Ao tentar se desligar, o chefe reteve sua carteira de trabalho e tentou lhe persuadir a permanecer no trabalho, e diante da negativa, negou a devolução da carteira (manifestação comportamental negativa). O pagamento de seu salário e a devolução de sua carteira só foi possível pela intervenção da MP (Missão Paz), que enviou uma das assistentes sociais para acompanhá-lo à empresa. Depois de se desligar da organização, retorna a MP e consegue outro emprego, em que teve sua carteira de trabalho assinada e passou a receber o salário em dia (experiência positiva).

\section{Participante 10 (mesa redonda)}

P10 é um empresário do ramo de alimentação que possui haitianos em seu quadro de funcionários. Conheceu a MP por uma reportagem na televisão e decidiu ir até lá para ajudar pelo menos um imigrante (emoção intergrupal positiva). Após passar pela palestra ministrada pela assistente social, modificou a maneira como pensava a respeito dos haitianos e passou a admirá-los (emoção intergrupal positiva). Relatou que foi influenciado pelo relato de outros empregadores que já haviam contratado imigrantes por intermédio da MP, que estavam lá no mesmo dia para recrutar mais haitianos. Descreve o caso de um senhor do Rio de Janeiro que havia contratado 30 haitianos e retornou para contratar mais 30 (manifestação comportamental positiva). Contou que foi até a MP com a intenção de contratar dois imigrantes, mas que optou por contratar oito nesse mesmo dia (manifestação comportamental positiva). Ao chegar à empresa, levou os novos empregados para conhecer as instalações e para fazer os exames médicos. No dia seguinte já estavam todos trabalhando e "trabalhando bem". Essa foi "uma das experiências mais marcantes de minha vida" (experiência positiva). Foi a partir do contato com esses imigrantes que o empresário teve a oportunidade de conhecer um pouco da cultura do Haiti e buscou mais informações acerca desse país (manifestação comportamental positiva), por quem diz possuir "profunda admiração" (emoção intergrupal positiva). 


\section{Participante 11 (mesa redonda)}

P11 é sócio de uma empresa de logística, que possui mais três sócios. Seu primeiro contato com os imigrantes se deu com a chegada de quatro haitianos na empresa. No princípio não conseguia se comunicar muito bem com eles por dificuldades com o idioma, mas ficou admirado com a educação deles (emoção intergrupal positiva). Contratou um intérprete para se comunicar com os imigrantes e a partir de então contratou mais haitianos, auxiliando aqueles que ainda não possuíam a documentação para trabalhar legalmente no país (manifestação comportamental positiva). Relatou que o quadro atual da empresa conta com noventa estrangeiros. Ao perceberem que havia interesse dos imigrantes em atividades religiosas, a empresa promoveu cultos religiosos, inclusive em outros idiomas (manifestação comportamental positiva). Contou ainda que os imigrantes são de grande ajuda, "por que assim, quantas vezes no domingo, no sábado à noite, o pessoal [brasileiros] não querem trabalhar e eles que tão ajudando a gente nesse dia-a-dia". Essa e outras experiências fizeram o empresário olhar para os imigrantes com empatia, compreendendo seus valores (emoção intergrupal positiva). Relata sentir-se bastante feliz com o êxito conseguido nas contratações (experiência positiva).

A tabela 3 apresenta as frequências de manifestação das categorias de análise em função do discurso dos participantes. As experiências negativas e de manifestações comportamentais negativas mencionadas pelos imigrantes são maiores que as positivas. No entanto, as emoções intergrupais, embora em menor número, foram mais positivas que negativas. Destaca-se que P2 demonstrou muitas experiências negativas em sua entrevista, se comparado aos outros casos.

Tabela 3 - Frequências das Emoções Intergrupais, Manifestações Comportamentais e Experiências

\begin{tabular}{lcccccc}
\hline & $\begin{array}{c}\text { Emoções } \\
\text { Intergrupais } \\
\text { Negativas }\end{array}$ & $\begin{array}{c}\text { Emoções } \\
\text { Intergrupais } \\
\text { Positivas }\end{array}$ & $\begin{array}{c}\text { Experiências } \\
\text { Negativas }\end{array}$ & $\begin{array}{c}\text { Experiências } \\
\text { Positivas }\end{array}$ & $\begin{array}{c}\text { Manifestações } \\
\text { Comportamentais } \\
\text { Negativas }\end{array}$ & $\begin{array}{c}\text { Manifestações } \\
\text { Comportamentais } \\
\text { Positivas }\end{array}$ \\
\hline Participante 1 & 1 & 0 & 2 & 1 & 3 & 3 \\
Participante 2 & 1 & 3 & 16 & 1 & 5 & 1 \\
Participante 3 & 1 & 2 & 1 & 2 & 0 & 4 \\
Participante 4 & 0 & 1 & 5 & 0 & 1 & 1 \\
Participante 5 & 0 & 0 & 0 & 3 & 0 & 0 \\
Participante 6 & 0 & 0 & 3 & 2 & 5 & 2 \\
Participante 7 & 0 & 0 & 2 & 1 & 1 & 1 \\
Participante 8 & 0 & 0 & 1 & 0 & 0 & 0 \\
Participante 9 & 0 & 0 & 1 & 1 & 2 & 0 \\
Participante 10 & 0 & 1 & 0 & 1 & 0 & 3 \\
Participante 11 & 0 & 2 & 0 & 7 & 0 & 2 \\
Total de imigrantes & 3 & 6 & 31 & 11 & 0 & 12 \\
Total de empresários & 0 & 3 & 0 & 8 & & 5 \\
\hline
\end{tabular}

A figura 1 apresenta dois diagramas de comparação, indicando a alocação dos participantes em termos das categorias analíticas: Emoções Intergrupais, Manifestações Comportamentais e Experiências positivas e negativas. 

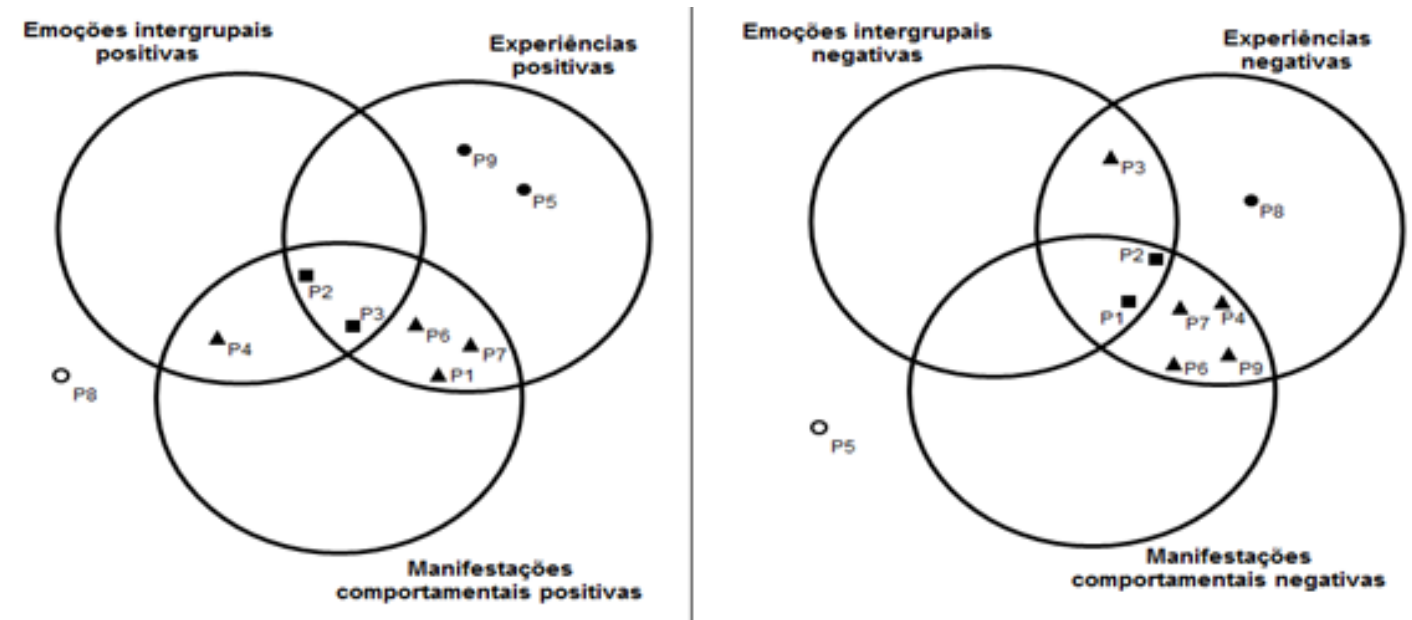

Figura 1 - Alocação dos imigrantes nas três categorias de análise: Emoções Intergrupais, Manifestações Comportamentais e Experiências dos Imigrantes em Positivas ou Negativas.

\section{Discussão}

Os participantes do estudo são seis homens e três mulheres oriundos da África, da Oceania e da América do Sul. Optaram pela imigração, em sua maioria, na busca de melhores condições de vida ou fugindo da situação política do seu país de origem. Com a exceção de apenas um, todos vieram desacompanhados de familiares, que permaneceram no país de origem para esperar o retorno do imigrante e imigrar também, caso o migrante se adapte à nova realidade local. Quatro deles manifestam vontade de retornar ao seu país. 0 tempo de permanência dos participantes no Brasil varia de três meses a cinco anos. Nesse período, trabalharam em diversos lugares, sujeitando-se aos serviços que surgiam, pela impossibilidade de escolha face à necessidade imediata de trabalho.

O estudo ilustra, a partir da caracterização dos seus participantes, a configuração imigratória no país neste período. Destaca-se o fato de a maioria dos participantes ser originária de localidades não caracterizadas historicamente pela atração de contingentes populacionais para o Brasil, como é o caso de países como o Haiti, o Congo, o Reino de Tonga e a Guiné-Bissau. Nesse sentido, Cavalcanti et al. (2014) apontam que diferente dos fluxos migratórios no século XIX e XX, que eram financiados pelo próprio governo brasileiro com o intuito de ocupar territórios e branquear a população, atualmente o Brasil vem recebendo um novo perfil de imigrantes face às contingências do mundo contemporâneo, em que se leva em conta problemas econômicos, conflitos políticos e catástrofes naturais.

Isto é corroborado pelas razões apontadas pelos participantes deste estudo, que alegam ter vindo para o Brasil em busca de melhores condições de vida e trabalho, fugindo da instabilidade política no país de origem. É o caso de um dos haitianos entrevistado (P2), que além dos dois motivos pessoais e de catástrofe, foi influenciado por um brasileiro atuante na Missão das Nações Unidas para a estabilização do Haiti. De acordo com Moraes, Mattos e Andrade (2013), essa influência, acompanhada pelo desenvolvimento econômico do Brasil até meados de 2014, antes da profunda crise pela qual este país atravessa na atualidade, e a catástrofe que abalou o Haiti em 2010, são os principais motivos de deslocamento desse contingente populacional. 
No que diz respeito à inserção no mercado de trabalho, observa-se a situação de instabilidade do imigrante. Os participantes da pesquisa afirmaram que devido às condições adversas oferecidas pelos empregadores, tais como moradia, salário e direitos trabalhistas, não conseguiam manter-se por muito tempo no mesmo emprego. É o que ocorreu com um dos participantes (P7) que está no quarto vínculo de trabalho. Além disso, é importante salientar que os participantes do estudo estão inseridos em áreas de pouco status e baixa qualificação no mercado de trabalho, mesmo aqueles que possuem maior nível educacional. Este fato pode estar relacionado com a perspectiva polarizada de inserção dos imigrantes no mundo do trabalho, pois, como afirma Villen (2012), nem todos os imigrantes conseguem se inserir em áreas valorizadas no mercado de trabalho. Há setores econômicos na produção nacional (financeiro, petroquímico, químico, energia, etc.) que contratam os imigrantes aproveitando seu nível de qualificação especializada, dando-lhes visibilidade e oferecendo melhores condições de salário e de trabalho - e quando é assim, a imigração para o trabalho faz uso de mecanismos e meios legais. No entanto, muitos imigrantes, principalmente provenientes de países periféricos, desempenham funções de baixa qualificação e vivem em condições precárias de trabalho e de emprego, como parece ser o caso dos participantes do estudo.

Neste sentido, verificou-se que existe uma grande oferta para os imigrantes na área da construção civil, por exemplo, conforme relato de um dos participantes (P2), com remuneração baixa. Pode ser reconhecida uma relativa melhora no que tange a tal inserção no mercado após a obtenção da documentação necessária, com destaque para a mediação da MP, no caso dos participantes da pesquisa. Devido a esta polarização, Vilela (2011) afirma que a nacionalidade do trabalhador favorece o preconceito e a discriminação, com impactos na posição ocupada pelo imigrante no mercado de trabalho local.

A amabilidade e a hostilidade dos nativos para com os imigrantes contribuem na adaptação e inserção no trabalho. Emoções intergrupais positivas ou negativas, experiências igualmente positivas ou negativas e manifestações comportamentais que sinalizam amabilidade e hostilidade de brasileiros para com estrangeiros visualizadas na Figura 1, deixam em evidência a interação e a posição dos participantes frente a essas relações. Ao analisar as relações entre emoções, experiências e comportamentos positivos de brasileiros para com o imigrante observa-se que P2 e P3 localizam-se no centro do diagrama, sinalizando que no geral, vivenciaram momentos de "companheirismo e diálogo" com seus colegas brasileiros no trabalho. Isto é evidenciado pelas manifestações comportamentais do colega brasileiro de P2 que o avisou sobre os comportamentos discriminatórios da sua gerente no trabalho e, também, do chefe brasileiro de P3, que o contratou, ofereceu comida e deu as coordenadas para ele poder realizar bem o trabalho. Essas experiências, portanto, revelam uma articulação entre emoções (sentimento de aproximação), comportamentos de ajuda, propiciando experiência positiva no trabalho.

Três participantes ( $P 1, \quad P 6$ e $P 7)$ mencionaram tanto experiências quanto comportamentos positivos. P1 demonstra o seu contentamento com o trabalho devido ao bom ambiente propiciado pelo seu chefe e pelos seus colegas brasileiros que o ajudaram e o ensinaram a desempenhar suas funções no trabalho; P6 relata sua experiência ao chegar na $\mathrm{CM}$ onde foi acolhida e recebeu ajuda jurídica para regularizar sua situação no Brasil e ter os seus direitos trabalhistas assegurados; e P7 descreve um comportamento positivo de uma de suas empregadoras que ao não poder assinar sua carteira como babá, indicou-a a uma amiga que a contratou, onde permanece até hoje, estando bastante satisfeita no emprego. 
Emoções intergrupais positivas associadas a comportamentos também positivos aparecem no relato de $\mathrm{P} 4$, ao descrever o quanto foi bem recebida pela MP sentindo-se acolhida na Casa do Imigrante.

As experiências positivas marcaram os relatos de dois imigrantes (P5 e P9). P9 relatou que depois de passar por dificuldades referentes aos direitos trabalhistas e ao salário em um dos seus empregos, conseguiu, por intermédio da MP obter um novo emprego onde sua carteira foi assinada e recebe seu salário em dia; já P5 após ter passado pelo Acre e pela Bahia, mostrou-se otimista com a chegada a São Paulo, e pela intermediação da MP conseguiu um emprego mais satisfatório.

A figura 1 apresenta diagramas que alocam os participantes do estudo nos círculos que representam as três categorias do estudo: experiências, emoções intergrupais e comportamentos negativos de brasileiros para com imigrantes. Dois imigrantes (P1 e P2) mencionaram as três categorias negativas. P1 relatou ter sofrido muito com o racismo aqui no Brasil, exemplificando isso com os comportamentos discriminatórios de pessoas no ônibus e metrô de São Paulo; enquanto P2 relatou um sentimento de superioridade e hostilidade da chefia no Brasil ("a chefe mesmo falou que meu país tá ruim, eu sou pobre, [...] eu sou negro"). Somado a esse fato, P2 ainda vivenciou um caso de discriminação no emprego anterior, quando a gerente espalhou comentários dizendo aos seus colegas que ele não tomava banho e que tinha um cheiro ruim. Esse participante foi o que mais mencionou experiências negativas no Brasil.

A menção a experiências negativas e comportamentos negativos esteve presente nos relatos dos participantes P4, P6, P7 e P9. A participante 4 relatou não ter sido ajudada pelo consulado de seu país no Brasil. Chegou a comer uma vez por dia nos finais de semana para mandar dinheiro aos filhos e percebeu que estava ganhando menos aqui no Brasil do que na Bolívia. P6 relata que na época em que trabalhava como professora, em Minas Gerais, constatou receber tratamento diferenciado. Por esse motivo, pediu demissão e foi trabalhar em um restaurante como garçonete, sendo que em pouco tempo se viu trabalhando sem receber salário. P7 relatou ter sido discriminada em seu primeiro emprego aqui no Brasil pelo fato de ser negra. P9, por sua vez, mencionou que após regularizar sua situação no Brasil, foi trabalhar em outro estado, durante oito meses, porém a empresa não o pagava corretamente e nem queria assinar sua carteira de trabalho.

O participante 3 mencionou em seu relato emoções intergrupais negativas e experiências negativas, afirmando que a discriminação com o negro ocorre em todo o mundo. O relato de P8 focou-se somente em experiências negativas, em virtude do insucesso de sua tentativa de imigrar para estudar no Brasil, sujeitando-se a trabalhos temporários subqualificados para tentar sobreviver.

A figura 1 retrata também haver sentimentos de ambivalência dos imigrantes nas interações com os brasileiros. Esse sentimento de ambivalência contrapõe-se com a crença compartilhada de que o Brasil é um país hospitaleiro, haja vista as diversas menções de comportamentos discriminatórios e de sentimentos hostis na experiência de trabalho do imigrante no Brasil. Nesse aspecto, os resultados deste estudo coincidem com os de Simai e Baeninger (2011), que alertam sobre o mito da receptividade do brasileiro. De acordo com as autoras, esse mito é conduzido por um discurso normativo de naturalização e mascaramentos de conflitos ideológicos referentes à integração dos imigrantes e outros grupos étnicos na sociedade brasileira, o que sugere que o mito da receptividade contribui 
para a negação da xenofobia no país, em especial aos imigrantes oriundos de países periféricos e de etnia negra. O relato apresentado por Kaly (2001), imigrante e sociólogo senegalês, sobre o "Ser Preto Africano no 'Paraíso Terrestre' Brasileiro" alerta que a maioria dos estudantes africanos que escolhem o Brasil como destino, o faz pela suposta "democracia racial" no país, o que de fato não ocorre na prática. Os negros imigrantes são tratados de modo discriminatório tanto como os negros nativos.

Um fator a ser levado em conta na análise é o fato de os participantes do estudo terem vindo, em sua maioria, da América Latina e África, o que pode explicar os sentimentos de superioridade e hostilidade dos brasileiros. O próprio Kaly (2001) cita um estudo desenvolvido por Lená Menezes que utilizou do depoimento de dois imigrantes, um francês e um angolano, para ilustrar esses sentimentos. O francês relatou haver um complexo de inferioridade do brasileiro frente aos estrangeiros oriundos de países desenvolvidos. Para ele, era comum ouvir perguntas, tais como: "Por que é que você veio para o Brasil?", "Não era melhor lá?". O angolano, que em princípio, poderia se sentir em casa, menciona sua surpresa com casos de preconceito no Brasil em relação ao negro estrangeiro. Essa discussão está em sintonia com os achados de Gondim et al. (2013) em que os imigrantes norteamericanos, europeus e asiáticos são vistos por brasileiros como grupos mais concorrentes no mercado de trabalho do que sul-americanos e africanos, provavelmente pelo menor status percebido relacionado às suas condições de desvantagens (guerras, pobreza, etc.). Quando se analisam grupos de imigrantes de diferentes origens com um destino semelhante observa-se que ao serem controladas as características dos indivíduos e da situação do mercado, a origem do imigrante mantém alta correlação com sua posição na estrutura hierárquica socioeconômica conquistada no país recebedor (Vilela, 2011).

Esses dados ressaltam o papel assimétrico das relações de poder e status social desenvolvidas na sociedade. Em estudo realizado na Espanha, Basade e Bobowik (2013) concluíram que os grupos latino-americanos possuem um maior status se comparados aos africanos e, por esse motivo, o processo de adaptação dos primeiros é mais fácil. Outros autores também afirmam que o elevado status e poder repercutem no viés intergrupal (Costa, Pereira, \& Monteiro, 2006), pois contribuem para aumentar comportamentos hostis com o intuito de manter status e recursos. Nesse sentido, e conforme assinala Sales (2014), apesar da crença fantasiosa de a identidade brasileira ser construída na base de traços de mestiçagem e de democracia racial que inclinariam os brasileiros a serem mais hospitaleiros e tolerantes para com os migrantes, observa-se que o tratamento para com eles depende do status percebido. O que nos leva a concluir que no Brasil o preconceito, o racismo e a discriminação contra os imigrantes se mantém, apesar de alguns avanços, e que esta rejeição é seletiva. Hostilidade, preconceito e discriminação são mais direcionados a grupos de imigrantes de menor status.

\section{Considerações finais}

Evidências de preconceito e discriminação de brasileiros contra estrangeiros, principalmente vindos da África e América Latina colocam em pauta o mito da hospitalidade nacional e reafirmam que tais manifestações podem ser agravadas por crise econômica, estereótipos e percepção de diferenças de status e poder social entre grupos humanos. Instituições que funcionam como mediadoras na adaptação do imigrante no Brasil tornam- 
se relevantes para oferecer suporte social e atenuar impactos negativos (Gonzáles-Castro et al., 2009).

Algumas limitações do estudo merecem destaque. Os imigrantes depoentes foram convidados pela entidade, Missão Paz, e tiveram pouco tempo para a exposição das suas experiências migratórias nas mesas redondas. Além disso, observou-se receio dos imigrantes entrevistados ao descreverem as suas experiências no Brasil, provavelmente pela condição de vulnerabilidade a que se encontram expostos. Esses aspectos exigem cuidado na interpretação dos dados e generalização dos achados, tendo em vista que podem não ser representativos da realidade da maioria dos imigrantes no Brasil.

\section{Referências}

Allport, G. (1954). The nature of prejudice. Reading: Addison Wesley.

Basade, N., \& Bobowik, M. (2013). Estatus grupal, discriminación y adaptación en inmigrantes latinoamericanos y africanos en España. Psicoperspectivas: Individuo e Sociedade, 12(1), 5-29.

Bardin, L. (1977). Análise de conteúdo. Lisboa: Edições 70.

Bauer, M. W. (2002). Análise de conteúdo clássica: uma revisão. In M. W. Bauer \& G. Gaskell (Eds.). Pesquisa qualitativa com texto, imagem e som: um manual prático (pp. 189-217). Petrópolis: Vozes.

Brzozowski, J. (2012). Migração internacional e desenvolvimento econômico. Estudos Avançados, 26(75), 137 156.

Cavalcanti, L., Oliveira, A. T., \& Tonhati, T. (2014). A Inserção dos imigrantes no mercado de trabalho brasileiro. Brasília: Cadernos do Observatório das Migrações Internacionais.

Cottrell, C. A., \& Neuberg, S. L. (2005). Different Emotional Reactionsto Different Groups: A Socio functional Threat-Based Approach to "Prejudice". Journal of Personality and Social Psychology, 88(5), 770-789.

Costa, P., Pereira, J., \& Monteiro, M. B. (2006). O papel do poder e do estatuto nas atitudes face aos direitos humanos dos imigrantes. Recuperado em 21 de abril de 2015, de http://www.psicologia.pt/artigos/ver_artigo.php?codigo=A0290.

Cuddy, A., \& Fiske, S. (2007). The BIAS Map: Behaviors from intergroup affect and stereotypes. Journal of Personality and Social Psychology, 92(4), 631-648.

Foot, F., \& Leonardi, V. (1982). História da indústria e do trabalho no Brasil. São Paulo: Global editora e distribuidora Ltda.

Friese, S. (2012). ATLAS.ti 7 User Manual. Berlin: ATLAS.ti Scientific Software Development GmbH.

Gondim, S., Techio, E., Paranhos, J., Moreira, T., Brantes, C., Bonifácio Sobrinho, J., \& Santana, V. (2013). Imigração e trabalho: um estudo sobre identidade social, emoções e discriminação contra estrangeiros. Psicologia em Pesquisa, 7(2), 151-163.

Gondim, S. M.G., \& Bendassolli, P. F. (2014). Crítica da relação teoria-fenômeno-dados na análise de conteúdo qualitativa. Psicologia em Estudo, 19(2), 191-199.

Gonzáles-Castro, J., Ubillos, S., Bilbao, M. A., Techio, E., \& Basade, N. (2009). A focus-group research into the lives of members of four inmigrant groups in Spain. Revista de Psicologia Social, 24(3), 381-398.

Hammersley, M. (2010). Reproducing or constructing? Some questions about transcription in social research. Qualitative Research, 10(5), 553-569.

Hodson, G., \& Costello, K. (2007). Interpersonal disgust, ideological orientations, and dehumanization as predictors of intergroup attitudes. Psychological Science, 18(4), 691-698.

Instituto Brasileiro de Geografia e Estatística (2010). Censo demográfico 2010. Recuperado em 10 de maio de 2015, de 
http://www.ibge.gov.br/home/presidencia/noticias/imprensa/ppts/00000008473104122012315727483 985.pdf.

Jost, J. T., Kivetz, Y., Rubini, M., Guermandi, G., \& Mosso, C. (2005). System-Justifying functions of complementary regional and ethnic stereotypes: cross-national evidence. Social Justice Research, 8(3). 305-333.

Kaly, A. P. (2001). O Ser Preto Africano no "paraíso terrestre" brasileiro: Um sociólogo senegalês no Brasil. Recuperado em 03 de maio de 2015, de http://www.lusotopie.sciencespobordeaux.fr/kaly.pdf.

Lima, M. E. O. (2013). Preconceito. In L. Camino, A. R. R. Torres, M. E. O. Lima \& M. E. Pereira (Orgs.). Psicologia Social: Temas e Teorias (pp. 589-640). Brasília: Technopolitik.

Mackie, D., Devos, T., \& Smith, E. (2000). Intergroup emotions: explaining offensive action tendencies in an Intergroup Context. Journal of Personality and Social Psychology, 79(4), 602-616.

Mackie, D., Smith, E., \& Ray, D. (2008). Intergroup emotions and intergroup relations. Social and Personality Psychology Compass, 2(5), 1866-1880.

Meertens, R. W., \& Pettigrew, T. F. (1997). Is subtle prejudice really prejudice? Public Opinion Quarterly, 61(1), 54-71.

Menezes, M. L. P. (2000). Tendências atuais das migrações internas no Brasil. Recuperado em 09 de março de 2015, de http://dialnet.unirioja.es/servlet/articulo?codigo=248734.

Ministério da Justiça. (2015). Brasil bate recorde na concessão de refúgio a estrangeiros. Recuperado em 23 de fevereiro de 2015, de http://www.justica.gov.br/noticias/brasil-bate-recorde-na-concessao-de-refugioa-estrangeiros.

Moraes, I. A., Mattos, B. R. B., \& Andrade, C. A. A. (2013). A Imigração haitiana para o Brasil: causas e desafios. Revista Conjuntura Austral, 4(20), 95-114.

Pereira, C. R., Vala, J., \& Costa-Lopes, R. (2010). From prejudice to discrimination: the legitimizing role of perceived threat in discrimination against immigrants. European Journal of Social Psychology, 40(7), 1231-1250.

Pires, A. (2008). Amostragem e pesquisa qualitativa: ensaio teórico e metodológico. In J. Poupart, J. Deslauriers, L. Groulx, A. Laperrière, R. Mayer \& A. Pires (Eds.). A pesquisa qualitativa: Enfoques epistemológicos e metodológicos (pp. 154-213). Porto Alegre: Vozes.

Sales, N. P. (2014). Os haitianos no Brasil e o mito da democracia racial. Trabalho de Conclusão de Curso, Universidade Estadual da Paraíba, Paraíba, Brasil.

Simai, S., \& Baeninger, R. (2011). The national myth of receptivity in Brazil. AmeriQuests, 8(1), 1-12.

Smith, E. R., Seger, C. R., \& Mackie, D. (2007). Can emotions be truly group level? Evidence regarding four conceptual criteria. Journal of Personality and Social Psychology, 93(3), 431-446.

Smith, E. R. (1993). Social identity and social emotions: toward new conceptualization of prejudice. In D. M. Mackie \& D. L. Hamilton (Eds.). Affect, cognition, and stereotyping (pp. 297-316). New York: Academic Press.

Souza, E. M. (2013). Migrações e políticas migratórias na globalização: os desafios político-sociais do Estado. Dissertação de Mestrado, Universidade Federal de Santa Maria, Rio Grande do Sul, Brasil.

Stephan, W. D., Boniecki, K. A., Ybarra, O., Bettencourt, A., Ervin, K. S., Jackson, L. A., Mcnatt, P. S., \& Renfro, C. L. (2002). The role of threats in the racial attitudes of blacks and whites. Personality and Social Psychology Bulletin, 28(9), 1242-1254.

Staffen, M. R., \& Nistler, R. (2014). Transnacionalidade e relações de trabalho: análise da imigração dos haitianos ao Brasil. Estamos preparados? Revista Eletrônica Direito e Política, 9(3), 1542-1568.

Tam, T., Hewstone, M., Cairns, E., Tausch, N., Maio, G., \& Kenworthy, J. (2007). The Impact of Intergroup Emotions on Forgiveness in Northern Ireland. Group Processes \& Intergroup Relations, 10(1), 119-135.

Tamer, A., \& Pozzeti, V. C. (2013). A Imigração haitiana e a criminalidade no Município de Manaus. Revista do Direito Público, 8(3), 55-76.

Tajfel, H. (1982). Grupos humanos e categorias sociais. Lisboa: Livros Horizonte. 
Villen, P. (2012). Polarização no mercado de trabalho e a nova imigração internacional no Brasil. Recuperado em 19 de abril de 2015, de http://www.estudosdotrabalho.org/texto/gt5/polarizacao.pdf.

Vilela, E. M. (2011). Desigualdade e discriminação de imigrantes internacionais no mercado de trabalho brasileiro. Dados, 54(1), 89-128.

Apresentação: 28/10/2015

Aprovação: 10/11/2016 